\title{
Doping of Conveyor Belt Materials with Nanostructured Fillers to Adapt Innovative Performance Characteristics
}

\author{
S. Falkenberg and L. Overmeyer
}

\begin{abstract}
The "conveyor belt" as a product represents a complex high performance component with a wide range of different applications. Further development of these highly complex components demands an integration of new technologies and new enhanced materials. In this context nanostructured fillers appear to have a more promising effect on the performance of the conveyor belt composite than conventional micro-scaled fillers.

Within the project "DotTrans" nanostructured fillers, for example silicon dioxide, are used to optimize performance parameters of conveyor belt systems. The objective of the project includes operating parameters like energy consumption or friction characteristics as well as adaptive parameters like cut or wear resistance.
\end{abstract}

Keywords-Conveyor belt, nanostructured fillers, wear resistance, friction characteristics.

\section{INTRODUCTION}

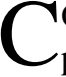
ONVEYOR belt systems represent complex high performance components with a wide range of different applications. Conveyor belts move baking goods into ovens, coal from coal mines to power stations or luggage from the airplane to the passenger. The high demands, which a highquality conveyor belt must meet under extreme conditions without damage, are various. Extended lifespan, higher transverse strength and reduced energy consumption are economical and ecological challenges. Therefore new conveyor belt concepts will become necessary.

With corresponding high research and developing costs belt manufacturers and plant operators try to optimize conveyor belts particularly regarding wear, their operational characteristics and thus their energy consumption as well as their wear resistance.

Fig. 1 shows a heavy duty application for purpose-built curved belt conveyors conveying limestone material.

S. Falkenberg is with the Institute of Transport and Automation Technology, Gottfried Wilhelm Leibniz University Hannover, 30823 Garbsen, Germany (phone: +49 511762 18159; e-mail: sascha.Falkenberg@ita.unihannover.de; web-page: www.ita.uni-hannover.de)

L. Overmeyer is with the Institute of Transport and Automation Technology, Gottfried Wilhelm Leibniz University Hannover, 30823 Garbsen, Germany (phone: +49 511762 3524; e-mail: ludger.overmeyer@ita.unihannover.de; web-page: www.ita.uni-hannover.de)



Fig. 1 Conveying limestone material on curved belt conveyors [12]

Regarding the further development of conveyor belts that will fit future requirements, new material concepts have to be applied. By means of selective insertion of nanostructured fillers into raw materials it is often possible to essentially improve the material characteristics. Hence, an interdisciplinary competence network was created to explore the use of nanostructured fillers for conveyor belt systems. This consortium includes leading conveyor and conveyor belt manufacturers, energy suppliers, nanotechnology companies and the Institute of Transport and Automation Technology (ITA) as member of the Faculty of Mechanical Engineering at the Leibniz University of Hanover. This research and development project is funded by the German Federal Ministry of Education and Research (BMBF) within the Framework Concept "Research for Tomorrow's Production" and managed by the Project Management Agency Research Centre Karlsruhe (PTKA). In several steps new research results in the field of nanotechnology are used to optimize operational characteristics like friction and energy consumption as well as adaptive material parameters, for example inflammability or wear and scratch resistance for different applications. In this context new testing technologies have been developed and are used at the ITA for practical testing and validation of the conveyor belt improvements. 


\section{CONVEYOR BELt SySTEMS}

Disregarding the field of application nearly all conveyor belts show a similar structure. They consist of a carcass or tension members that provide linear strength and shape embedded in an elastic matrix.

Due to a requirement of high tensile strength the carcass of conveyor belts in the field of mining industry applications generally consists of steel cords or fiber strands, which are embedded in a matrix of rubber materials. Figure. 2 shows the structure of a steel cord conveyor belt used in brown coal extraction. [8]

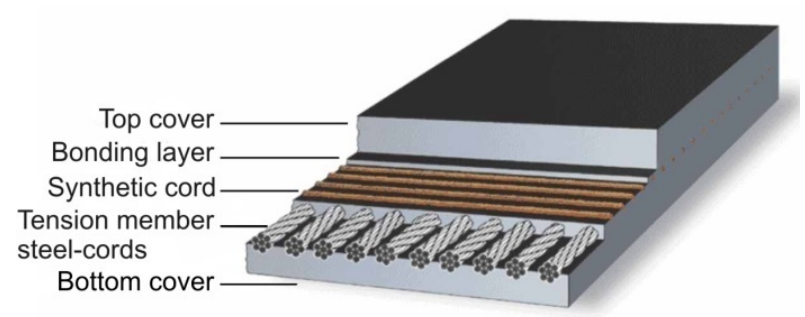

Fig. 2 Structure of a steel cord conveyor belt [12]

On the other hand in conveyor belts which are used in the field of intralogistics and transport of light bulk materials the tension member is formed by synthetic fiber or fabrics. The surrounding matrix consists of plastic materials like thermoplastic polyurethane elastomers (TPU), for example.

Whether the support of the conveyor belts in the conveyor system is realized by idler rollers or by tables, friction and wear occur during their operation. This occurrence of friction and wear certainly limits the maximal length of the belt conveyor and essentially affects its energy consumption.

At idler roller supported conveyor belts for horizontal guided conveying systems in the field of mining industry, with $60 \%$ of the running resistance, the rolling resistance represents the most relevant part [1, 7].

At table supported conveyor belts the energy consumption of the conveying system is mainly determined by the interaction of the friction partners - conveyor belt and table surface. In both fields further improvements that could be made by use of conventional techniques are limited. [10, 11]

That is the starting point of the project DotTrans. Preliminary research by several conveyor belt manufacturers shows that is possible to significantly affect the functional material characteristics by a modification of the material composition on the nano-scale. Hence nanostructured materials are used to achieve a reduction of friction and the rolling resistance of the conveyor belts.

\section{III.NANOSTRUCTURED FILLERS - IMPROVEMENT OF OPERATIONAL CHARACTERISTICS}

The durability of a conveyor belt is strongly affected by its wear resistance. With the help of nanostructured fillers new characteristics can be applied to the conveyor belt which have a positive effect on the wear behavior.

When polymer materials are observed inside a tribology system, it could be shown that nanostructured ceramic fillers in the polymer material are suitable for a significant reduction of abrasive wear. This additional will lead to extended durability of the components and higher economic efficiency. Figure. 3 shows a transmission electron microscope (TEM) image of a polymer doped with nanostructured $\mathrm{SiO}_{2}$-particles.

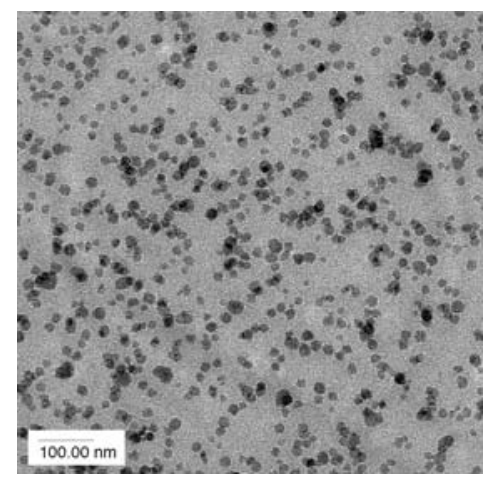

Figure.3 Transmission electron microscope image of a polymer doped with nanostructured $\mathrm{SiO}_{2}$ particles manufactured by nanoresins AG [2].

Reduced to a size of a few millionth of a millimeter conventional materials like silicates develop new amazing characteristics. Formerly dull paint becomes clear and a brittle compound becomes elastic.

By inserting nanostructured fillers into a raw material its properties could often be improved for a specific function. For example the elasticity modulus of a polymer could be increased which would lead to an enhanced mechanical load capacity. Mechanical strength, impact strength and fracture toughness can be improved or are at least not weakened, which sometimes could be observed in conventionally filled micro composites.

Reducing the diameter of a sphere the surface size-volume ratio is steadily increasing. Hence the surface size increases at a constant weight. Regarding particle diameters beneath 100 $\mathrm{nm}$ the size of the surface follows an exponential behavior, which can be obtained from the red curve in Figure.4.

In this dimension properties of the body are dominated by its surface. A large surface size offers for example a better connection of fillers to the raw material, because the connection mainly takes place on the surface.

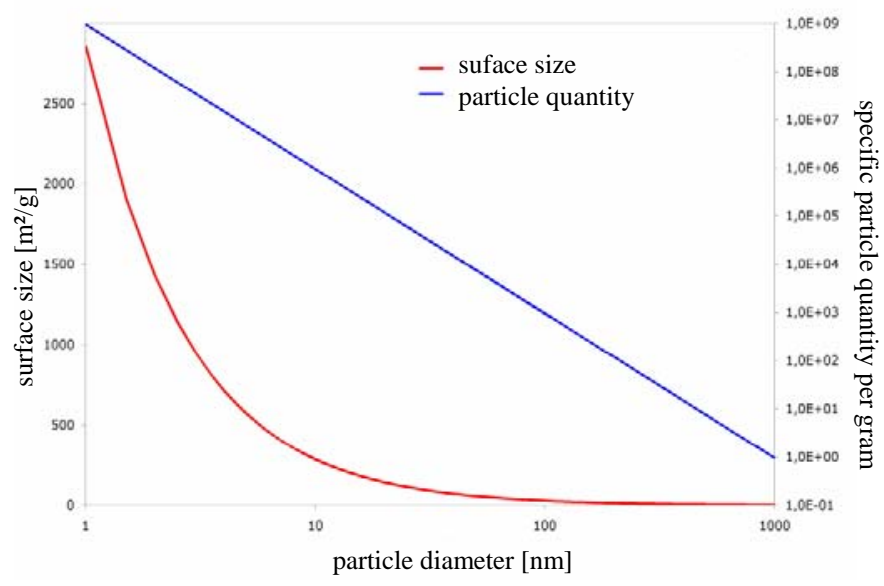

Figure.4 Surface size and specific particle quantity per gram in relation to the particle diameter [2]. 
At the same time the number of substance-particles per gram is remarkably growing. Regarding the specific particle quantity at a grain size of $1000 \mathrm{~nm}$ compared to $25 \mathrm{~nm}$ it could be obtained from the blue curve in Figure. 4 that the total mass is distributed among 60.000 times more particles.

The nanoscaled fillers does not increase the viscosity of compounds to the same extend as conventional micro-scaled fillers do. This facilitates the processing and makes highlyfilled formulation for coatings possible in the first place, to mention just one example. This on the other hand is a requirement for high wear resistance and low friction coefficients. In fields where transparency is required, varnish coatings, for example, the small particle size cause filled systems to be completely transparent. For applications in fiber glass - and carbon fiber composites it is important that the small nano-scaled particles are not refined in fiber-reinforced composites. They completely penetrate the fabric.

Up to now mainly fibers and particles were used in the scale of micrometers. Smaller nanostructured fillers seem to have a far greater effect on the performance potential of composite materials applied either alone or in combination with conventional micro-scaled fillers. For example a system composed of micro-corundum $\left(\mathrm{Al}_{2} \mathrm{O}_{3}\right)$ and nano-scaled silica in acrylate-films (PPTTA) experiences a wear resistance improvement of $4000 \%$ [2].

It can frequently be observed that already with a small concentration of nanostructured fillers in the material the requested improvements can be achieved. The optimal properties (for example a specific rate of attrition, friction coefficient or impact strength) are already produced by a concentration smaller than $10 \%$ of the substance. So the fracture toughness of diglycidyl ether of bisphenol A (DGEBA) epoxy resin can be increased by $27,5 \%$ with a concentration of $4 \%$ by weight nano-scaled $\mathrm{SiO}_{2}$-particles up to $55 \%$ increasing with a concentration of $7,8 \%$ by weight of the substance [3].

It is common for many former procedures to use particles that are not separated inside the composites. Pyrogenic silicic acids have a primary particle size and surface comparable to nanostructured fillers, for instance. Contrary to nanostructured fillers, the primary particles exist as aggregates. That means that a few hundred particles are combined in a compound. Because of this agglomeration a lot of advantages of the nanotechnology disappear. Consequently, one of the main objectives is to generate composite materials with separated nano-scaled particles.

\section{IV.APPLICATION OF NANOSTRUCTURED FILLERS IN CONVEYOR BELTS}

Conveyors represent a special challenge. Conveyor belts are often constructed similary, but there are a lot of different substrates like different types of rubber. In addition to the various types of materials, the current procedures are all solvent-based. Hence these procedures are only suitable to a limited extent for a modification of rubber materials. Furthermore, using solvents is indicated as harmful to the environment.

During the project DotTrans nano-scaled silica particles were generated, which are dispersible in raw mixtures of rubber. In cooperation with the participated conveyor belt manufactures it was possible to generate and analyze the correspondent composites.

Hence, the development of standardized testing technologies and therefore the technical measurement and characterization of the operational conveyor belt characteristics appears as a third objective of the project. As one of the main tasks, comparable characteristic data concerning energy consumption as well as wear resistance are defined for the first time. These will be determined by benchscale tests with test specimen as well as by component tests with conventional and modified conveyor belts. The newly discovered results are directly used for conceptual design of standardized testing technologies, which for the first time allows for a conveyor belt categorization regarding energy consumption and wear resistance comparable to a benchmarking test. The improvement of the conveyor belts by an inclusion of nano-technological procedures can be quantified only by the development of these adapted testing methods.

The quality of the conveyor belts that are used in the field of intralogistics and transport of light bulk materials can be described substantially by characteristic data regarding the friction between the friction partners as well as by characteristic data concerning the wear-resisting quality. For these quality criteria appropriate testing devices were provided and used for the evaluation of the material properties.

\section{A. Reduction of Friction and Energy Consumption}

Friction represents an interactive process of contacting bodies or materials and results inside the conveying system from the relative movement between conveyor belt and correspondent counterparts. Measured friction coefficients do not describe the characteristic of an individual body or material; it has to be referred to the specific tribological system. Therefore actual operating conditions are copied and analyzed to a large extent by means of conveyor belt systems in line with the standard application. After the development of suitable run side coatings based on TPU and isocyanate with nano-scaled silicate particles, volume samples in the chemical laboratory as well as larger volume samples with a belt with of $500 \mathrm{~mm}$ were produced and tested.

During the production of the run side coatings no problems with the homogeneity have been observed. Therefore, the mixing sequence of the single components is crucial. For research isocyanate and nano-scaled $\mathrm{SiO}_{2}$-particles comparisons with formulations that contain wax were included apart from the formulation with TPU. This was considered because technically it is common to include waxes for the decrease of the friction coefficient in polymer matrices. Thereby possibilities for already existing product rows with wax-containing run side coating, should be considered. As wax filler Carnauba-wax was used. With appropriate measures an agglomeration of the wax-particles could be prevented.

A separation or sedimentation of the coating pastes did not occur during the minimum open time of 12 hours. The coating 
formulations that are covered in this paper are shown in Table.1.

Table.1 Coating formulations tested for TPU-based conveyor belts

\begin{tabular}{|l|l|}
\hline Raw Material & Fillers \\
\hline $\begin{array}{l}\text { Thermoplastic Polyurethane } \\
\text { Elastomer (TPU) }\end{array}$ & $\begin{array}{l}\text { Standard coating without wax or nano- } \\
\text { scaled } \mathrm{SiO}_{2}\end{array}$ \\
\hline $\begin{array}{l}\text { Thermoplastic Polyurethane } \\
\text { Elastomer (TPU) }\end{array}$ & $\begin{array}{l}\text { Doped with nano-scaled } \mathrm{SiO}_{2} \text {, without } \\
\text { wax }\end{array}$ \\
\hline $\begin{array}{l}\text { Thermoplastic Polyurethane } \\
\text { Elastomer (TPU) }\end{array}$ & $\begin{array}{l}\text { Doped with wax, without nano-scaled } \\
\mathrm{SiO}_{2}\end{array}$ \\
\hline $\begin{array}{l}\text { Thermoplastic Polyurethane } \\
\text { Elastomer (TPU) }\end{array}$ & $\begin{array}{l}\text { Doped with nano-scaled } \mathrm{SiO}_{2} \text { (silica } \\
\text { based) and wax particles }\end{array}$ \\
\hline
\end{tabular}

During the research the wax and the nano-particle concentrations were kept constant.

The conveyor belt test samples with the applied coatings, displayed in Table.1, were produced in a coating device of a conveyor belt calander. Coatings were applied to two different types of conveyor belts. One type is designed with a fabric underside, where the coating fulfills the function of an impregnation and one type where the conveyor belt is provided with an additional TPU-bottom cover similar to the top face. Figure. 5 shows the structure of a TPU-based conveyor belt used in intralogistic applications.



Figure.5 Structure of a TPU-based conveyor belt used in intralogistic applications

In each case the coatings were newly manufactured. The reproducibility of the coatings was proven by repetition of the coating production and different testing applications.

The measurements of the friction characteristics of the manufactured conveyor belt samples were performed at two different test rigs. An examination of the static friction coefficient was performed at a friction coefficient testing device, before conveyor belts samples were tested in a testing device for the dynamic friction.

Steel was chosen as friction partner. The friction coefficient was determined as quotient of friction force and applied load. The measurement of the static friction coefficient of the coating on the polyurethane run side with an additional TPUbottom cover showed a reduction from $\mu_{\mathrm{s}}=0,55$ (TPU- based coating with isocyanate hardener, without wax, without nanoscaled $\mathrm{SiO}_{2}$ ) to $\mu_{\mathrm{s}}=0,22$ (TPU-based coating with isocyanate hardener, with nano-scaled $\mathrm{SiO}_{2}$, without wax). This corresponds to a reduction of the static friction coefficient of
60\%. A TPU-based coating doped with wax, without nanoscaled $\mathrm{SiO}_{2}$ led to a friction coefficient of $\mu_{\mathrm{s}}=0,42$.

Identical testing was undertaken at the conveyor belt with a fabric run side. All coatings used at fabric run sides, including uncoated polyester run side references, were tested with friction coefficients near $\mu_{\mathrm{s}}=0,15$. Hence the static measurements do not provide the required resolution to indicate differentiations for the different coating types of the fabric run side. Therefore additional comparative dynamic measurements were performed.

For a laboratory examination of dynamic friction characteristics concepts for a testing device were developed. In line with actual practice an existing testing device was modified, in order to simulate the material requirements as exactly as possible. A small belt sample is driven by a motor drum with a diameter of $200 \mathrm{~mm}$ and run over a fixed steel shaft with a diameter of $40 \mathrm{~mm}$. The torque of the motor drum and the temperature in the friction contact area, which are determined by occurring friction coefficients, were measured.

The configuration of the testing device used for a laboratory examination of the dynamic friction characteristics is shown in Figure.6.

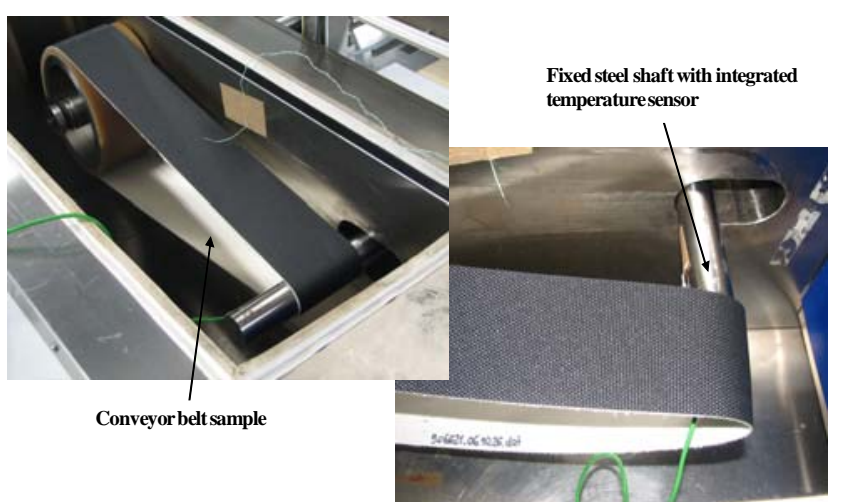

Figure.6 Testing device used for measurements of torque and temperature behavior over a period of time [5].

It could be gained from Figure.8 that the dynamic examination of the conveyor belts samples indicate that the TPU-based run side coatings doped with nano-scaled $\mathrm{SiO}_{2}$ (silicate based) showed equivalent or improved friction characteristic compared to the raw polyester run side references without additional coating. Therefore the required torque shown in Figure.7 can directly be attributed to the occurring friction forces at the contact area between the conveyor belt run side and the steel shaft surface.

Furthermore, the temperature in the friction contact area could directly be assigned to the energy loss caused by friction as given in the equation $[4,6]$ :

$$
\mathrm{E}=\mu_{2} \int F_{\mathrm{y}}(x) d x
$$

In this equation $\mu_{2}$ represents the kinetic friction coefficient and $\mathrm{F}_{\mathrm{N}}$ represents the normal force. 


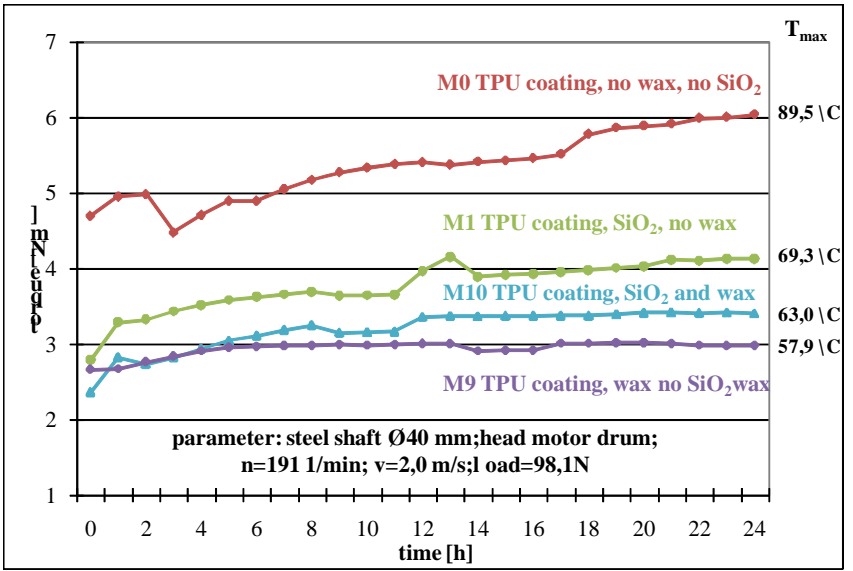

Figure.7 Torque behavior of conveyor belts with fabric underside run side coatings for project DotTrans [5].

The comparison of the TPU-based run side coatings of the fabric underside with and without nano-scaled $\mathrm{SiO}_{2}$ particles already shows a substantially reduced friction coefficient for coatings doped with nano-scaled particles at doping quantities of $3 \%$ by weight. A comparison is shown in Figure.8.

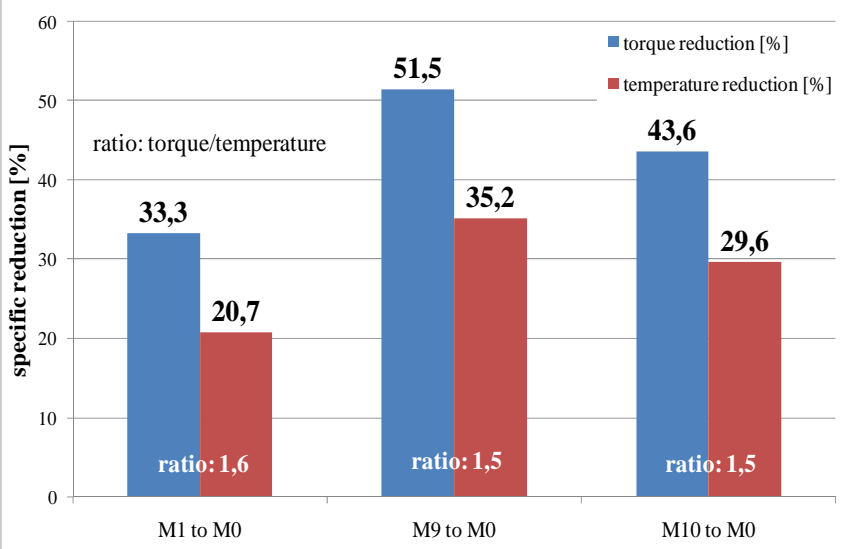

MO: TPU coating M1: TPU with $\mathrm{SiO}_{2}$-part. M9: TPU with wax M10: TPU with $\mathrm{SiO}_{2}$-part and wax

Figure.8 Comparison of the specific reduction of the torque and the temperature for fabric underside run side coatings for project Dot Trans [5]

An addition of waxes shows an additional reduction of the occurring friction forces. Although for an effective use of waxes a minimum temperature must be achieved for their activation, the nano-scaled particles already cause a reduction of the friction on the low temperature range.

The testing of the modified and reference conveyor belts with a bandwidth of $500 \mathrm{~mm}$ for intralogistic applications was performed at the friction coefficient testing device shown in Figure.9.

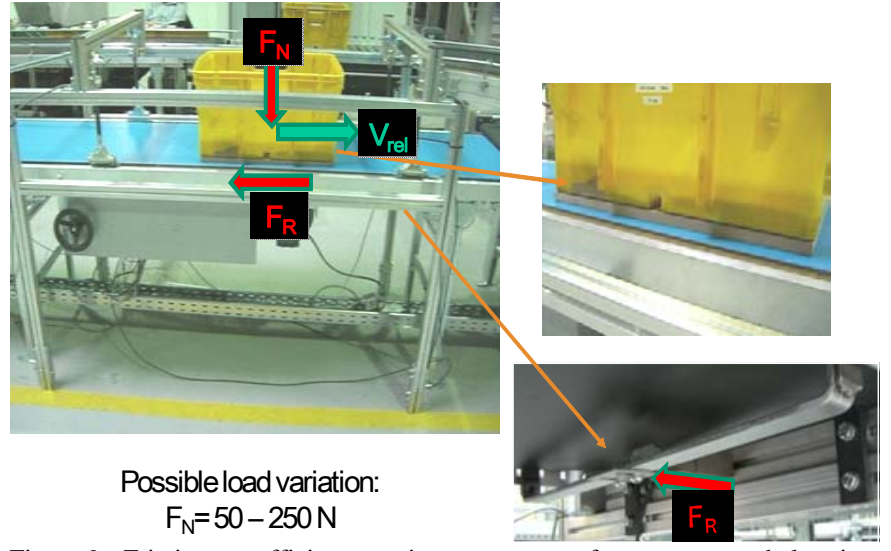

Figure.9 Friction coefficient testing conveyor for conveyor belts in intralogistic applications [6]

With this testing device it is possible to examine components and samples of variable forms and material compositions. In the testing conveyor the belt sample runs over a sliding table. The load can be varied with the help of the sand-filled container units which apply a evenly defined distributed load to the conveyor belt whereby an uncoupling of the load from the running distance is possible. The determination of the horizontal running friction force takes place at the table as a function of the load as given in the equation for coefficients of kinetic friction $[4,6]$ :

$$
\mu_{k}=\frac{F_{z}}{\nabla_{x}}
$$

In this equation $\mu_{\mathbb{Z}}$ represents the kinetic friction coefficient, $\mathrm{F}_{\mathrm{N}}$ represents the load and $\mathrm{F}_{\mathrm{f}}$ the occurring friction forces.

For the examination of the conveyor belt test samples with a bandwidth of $500 \mathrm{~mm}$ the same coatings as used in laboratory testing, were applied. They, too, can be obtained from Table.1. The measurements were performed with variation of load and relative speed to determine possible effects in the friction coefficient. Plywood tables with a coating of phenolic resin were chosen as friction partner due to the fact that these table types are commonly used as conveyor belt support in intralogistic applications. Hence, the friction coefficient can vary from those given by the laboratory testing.

Measurements of the kinetic friction coefficient for $\mathrm{SiO}_{2}$ doped coatings on the polyurethane run side showed a reduction up to $45 \%$ compared to conveyor belt samples without additional run-side coating. 


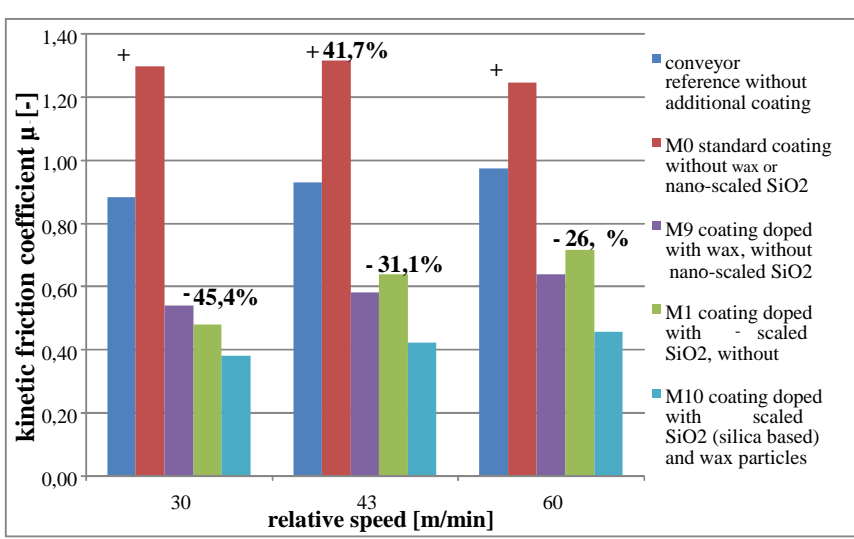

Figure.10 Compared friction coefficients for different run side coatings and testing speeds of the project DotTrans

An addition of waxes shows an additional reduction of the occurring friction forces. The measured friction coefficient for three different relative speeds can be obtained from Figure.10 and Figure.11.

Compared to conveyor belts with no additional run side coating it can be shown that a pure TPU-base coating with no additional fillers causes a strongly increased friction coefficient. Variation of the relative speed did not show severe or unexpected effects on the measured friction coefficients.

The shore hardness of the conveyor belt surface could be obtained from Table.2.

Table.2 Results of shore-hardness tests for different run side coatings of the project DotTrans

\begin{tabular}{|l|l|}
\hline Coating type & Shore-hardness \\
\hline $\begin{array}{l}\mathrm{M} 0 \text { standard coating without wax or nano-scaled } \\
\mathrm{SiO}_{2}\end{array}$ & 90 \\
\hline $\begin{array}{l}\mathrm{M} 1 \text { coating doped with nano-scaled } \mathrm{SiO}_{2} \text {, without } \\
\text { wax }\end{array}$ & 89 \\
\hline $\begin{array}{l}\mathrm{M} 9 \text { coating doped with wax, without nano-scaled } \\
\mathrm{SiO}_{2}\end{array}$ & 88 \\
\hline $\begin{array}{l}\mathrm{M} 10 \text { coating doped with nano-scaled } \mathrm{SiO}_{2} \text { (silica } \\
\text { based) and wax particles }\end{array}$ & 90 \\
\hline
\end{tabular}

The measurements of the hardness showed similar results, which are important for a required flexibility of the conveyor belt and the wear resistance of the coating.

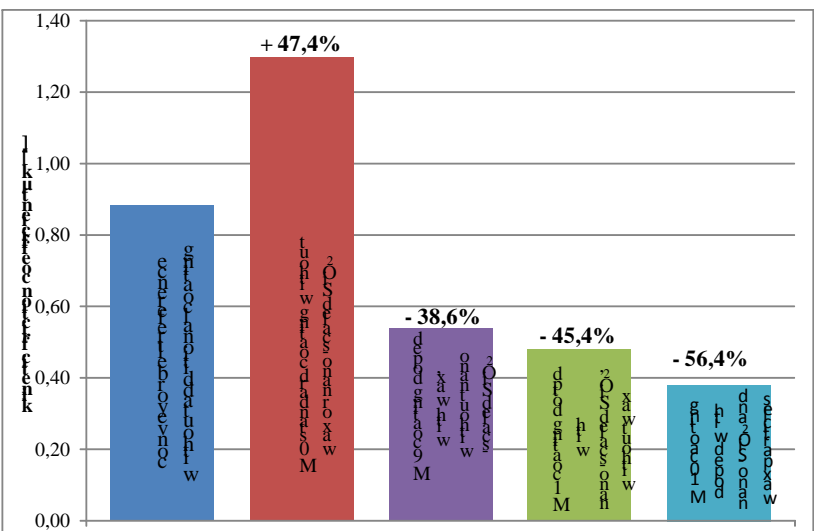

Figure.11 Compared friction coefficients for different run side coatings of the project DotTrans
As mentioned above, high friction coefficients cause energy loss due to occurring friction forces. Therefore the frictiondependent temperatures have been determined at friction contact areas caused by fixed elements of the belt conveyor system. Under a variation of different operational parameters, such as speed and load, measurements were performed at conveyor belts with a fabric underside doped with nanostructured fillers as well as on reference standard conveyor belts without additional coating. Characteristic temperature profiles for a 14 hour period of coating formulations tested for TPU-based conveyor belts during the project are illustrated in Figure.12.

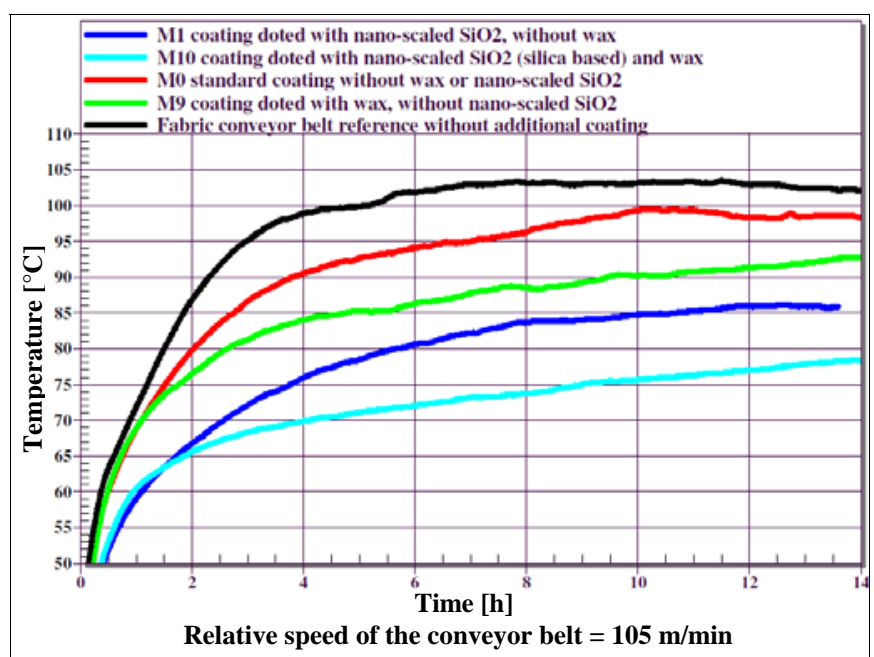

Figure.12 Maximum temperature behavior for conveyor belts with fabric underside run side coating within the project DotTrans

The reference standard conveyor belt (black curve, Figure.12) without additional coating and the conveyor belt with a standard TPU-coating generated the most critical maximal temperature with temperature around $100^{\circ} \mathrm{C}$. Temperature levels higher $90^{\circ} \mathrm{C}$ are critical to coatings and conveyor belts based on a TPU-system and leads to a serious reduction of the conveyor belt durability caused by pyrolysis.

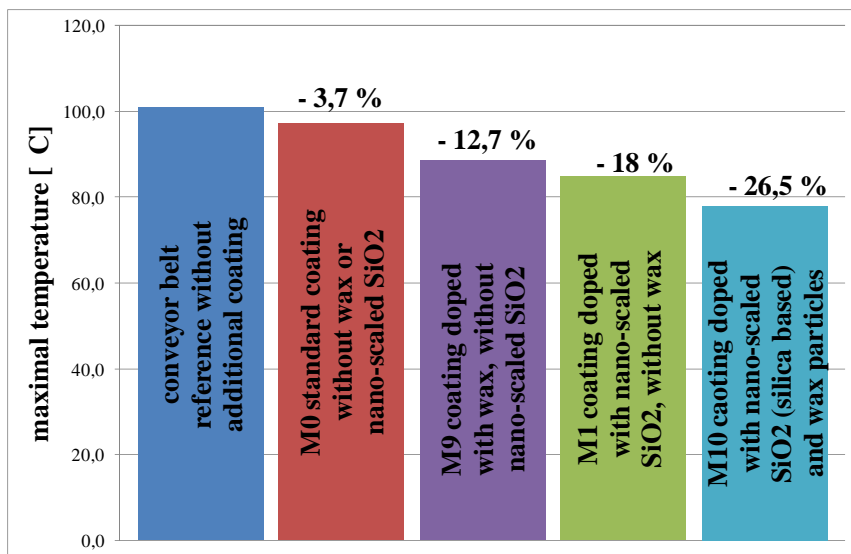

Figure.13 Comparison of maximum temperature behavior for conveyor belts with fabric underside run side coating within the project DotTrans 
As seen on Figure.12, the dynamic examinations of the conveyor belts samples indicate, correlating to result in Figure.7, that the TPU-based coatings doped with nano-scaled $\mathrm{SiO}_{2}$ have improved friction characteristics compared to the raw polyester run side references without additional coating. Coatings doped with nanostructured $\mathrm{SiO}_{2}$-fillers (dark blue curve, Figure.12) provide a possible reduction of the frictiondependent temperatures beneath temperature levels critical TPU-materials. A comparison of the maximum temperatures after a 14 hour period is shown in Figure.13.

Also, during the laboratory testing an addition of wax fillers to the nanostructured fillers shows an additional reduction of the occurring friction forces. The temperature in the friction contact area could directly be assigned to the energy loss caused by friction. It follows that the application of conveyor belt materials enhanced with nanostructured fillers, for example $\mathrm{SiO}_{2}$, a significant reduction of the energy consumption can be achieved even on a macroscopic scale. During all tests it became evident that the durability of the coatings doped with nanostructured fillers or wax particles against wear appears as high as that of untreated fabric or TPU-run sides.

Verified by the testing results in line with actual practice, which correlate to the results determined in laboratory testing, nanostructured fillers appear to have a promising effect on the performance of conveyor belt composites.

\section{V.CONCLUSION}

This paper presents an approach of improving performance characteristics of conveyor belts by doping the conveyor belt materials with nanostructured fillers.

In summary it can be stated that by using nanotechnological procedures rather than conventional methods a milestone can be reached in the development of conveyor belt systems. It was shown that the comparison of TPU-based coatings of the run side using nanostructured fillers lead to substantially smaller friction coefficients resulting in improved energy consumption. The main objective of the project DotTrans is therefore to develop new conveyor belts with clearly improved characteristics utilizing these nanotechnological procedures. As procedures of nano-technology in particular the doping with nano-particles such as silicon oxide with diameters between in a range between 10 and 30 Nm, so-called nano-composites are analyzed. The distribution of particles, the mixing condition and the properties of the vulcanized material specimens are subject of further investigations.

With the use of new procedures the fascinating properties of nanostructured materials are usable for various types of materials like classic rubber material.

With a development of new, optimized materials it is possible to ecpand the technological lead over international competitors.

The use of new, comparable testing methods makes it possible to quantify these improvements in line with actual practice.

Additionally, a common ground is created to design products with new dimensions and characteristics and to open new areas of application.

\section{ACKNOWLEDGMENTS}

This work was supported and funded by the German Federal Ministry of Education and Research (BMBF) within the Framework Concept "Research for Tomorrow's Production" and managed by the Project Management Agency Research Centre Karlsruhe (PTKA). In addition, the work was technically supported by leading conveyor manufacturer Transnorm System GmbH, the conveyor belt manufacturers Forbo Siegling GmbH and ContiTech conveyor belt systems AG as well as the nanoresins AG as the nanotechnology supplier.

\section{REFERENCES}

[1] A. Hintz, Einfluss des Gurtaufbaus auf den Energieverbrauch von Gurtförderanlagen. Diss., Universität Hannover, (1993)

[2] Internal results using Nanocryl C165 of the nanoresins AG.

[3] B. R. K. Blackman, A. J. Kinloch, J. Sohn Lee, A.C. Taylor, R. Agarwal, G. Schueneman, S. Sprenger, The fracture and fatigue behavior of nanomodified epoxy polymers. Journal of Materials Science 42, 7049-7051, (2007)

[4] H. Czichos, K.-H. Habig, Tribologie-Handbuch, Reibung und Verschleiß; Wiesbaden; Vieweg, (1992)

[5] Internal research of Forbo Siegling GmbH.

[6] K.-G. Scholz, Tribologie der Elastomere, Anwendungs- und Prüftechnik des elastomeren Verschleißschutzes; (2006)

[7] F.-O. Geesmann, Experimentelle und theoretische Untersuchungen der Bewegungswiderstände von Gurtförderanlagen. Dissertation Universität Hannover, (2001)

[8] A. Hintz, Einfluss des Gurtaufbaus auf den Energieverbrauch von Gurtförderanlagen. Dissertation Universität Hannover, (1993)

[9] A. Kropf-Eilers, Schadensbildung an Stahlseilfördergurten. Dissertation Universität Hannover, (1997)

[10] F. Scholl, Beitrag zur Bestimmung des Eindrückrollwiderstandes von Gurtförderern, Dissertation Universität Hannover, Berlin: Pro Business, (2004)

[11] F.-M. Wolpers, Untersuchungen zum Verschleißverhalten von Fördergurten. Dissertation Universität Hannover, 1989.

[12] Internal research of Phoenix conveyor belt systems

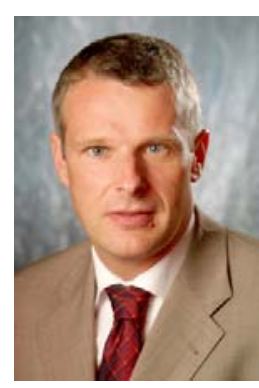

Prof. Dr.-Ing. Ludger Overmeyer studied electrical engineering at the University of Hannover, Germany. After receiving his $\mathrm{PhD}$ in production technology he held different positions in a number of industrial companies. Before he became head of the Institute for Transport and Automation Technology at the Leibniz University of Hannover in 2002 he was head of Research and Development at the Mühlbauer AG, Germany.

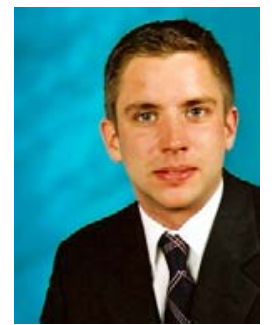

Sascha Falkenberg studied Mechanical Engineering at the Technische Universität Braunschweig. Since 2006 he works as a scientific engineer at the Institute of Transport and Automation Technology of the Leibniz University of Hannover, where he is the team leader of the transport technology department. He is active as well in committees, such as the FABERG Bureau of Standards. 